\title{
DISTRIBUSI UKURAN IKAN HASIL TANGKAPAN PURSE SEINE KM. BINTANG SAMPURNA-B DI WPP 572 DAN 573
}

\section{SIZE DISTRIBUTION OF PURSE SEINE FISH CATCH KM. BINTANG SAMPURNA-B IN FMA 572 AND 573}

\author{
Aditya Bramana, Liya Tri Khikmawati, Noar Muda Satyawan, Ario Anggara Mukti \\ Program Studi Perikanan Tangkap, \\ Politeknik Kelautan dan Perikanan Jembrana, Bali \\ Korespondensi: aditbramana@gmail.com
}

\begin{abstract}
The fisheries sector has a strategic role in national development. WPP 572 and 573 are the broad waters and located in the Indian ocean. This area has a quiet fish potential, especially from group of pelagic fishes as skipjack tuna, bigeye tuna, mackerel scad, yellowfin tuna, Indian mackerel, and mackerel tuna. However, in terms of utilization of fish resources, WPP 572 and 573 are currently experiencing a fully exploited period, especially for small and large pelagic fish. One of the methods to overcome fully exploited conditions is by managing the limitation on the size of fish that are fit to be caught. The method used in this research was a descriptive method. The sample was taken based on the purposive sampling method, by taking several types of fish caught according to their respective types which were considered to represent all the fish that had been caught. The number of fish samples adjusts to the capacity of the large pan which contains 18-20 large fish, and 50-100 small fish. The total number of catches was 75,878 kg. The main catch was $57,435 \mathrm{~kg}$ and bycatch was 18,443 kg. Percentage of catches were skipjack tuna (72\% feasible, 28\% unfit), baby tuna (100\% unfit), yellowfin tuna (51\% feasible, $49 \%$ unfit), mackerel scad, mackerel tuns, dolphinfish, and other fish (100\% feasible). The whole fish caught in KM Bintang Sampurna-B according to the number of samples measured shows that $74 \%$ are fit to catch and $26 \%$ are not fit to be caught.
\end{abstract}

Keyword: Indian Ocean, selectivity, worthy of catch

\begin{abstract}
ABSTRAK
Sektor perikanan memiliki peranan strategis dalam pembangunan nasional. WPP 572 dan 573 merupakan perairan luas dan berada di Samudera Hindia. Wilayah perairan ini memiliki potensi ikan yang cukup besar, utamanya dari kelompok ikan pelagis seperti cakalang, tuna mata besar, layang, madidihang, kembung, dan tongkol. Namun dalam segi pemanfaaatan sumberdaya ikan, WPP 572 dan 573 saat ini sudah mengalami masa fully-exploited khususnya untuk ikan pelagis kecil dan besar (KEPMEN KP 2017). Salah satu cara dalam mengatasi kondisi fully-exploited yaitu dengan pengelolaan pembatasan ukuran ikan yang layak tangkap. Metode yang digunakan dalam penelitian ini adalah metode deskriptif. Sampel yang diambil berdasarkan metode purposive sampling yakni dengan mengambil beberapa jenis ikan hasil tangkapan sesuai jenisnya masing-masing yang dianggap dapat mewakili keseluruhan ikan yang sudah ditangkap pada setiap setting. Jumlah sampel ikan menyesuaikan dengan kapasitas loyang besar tersebut yang berisikan 18-20 ekor untuk ikan besar, dan 50-100 ekor ikan kecil. Jumlah keseluruhan hasil tangkapan yang telah dilakukan mendapat hasil sebanyak $75.878 \mathrm{~kg}$. Hasil tangkapan utama sebanyak $57.435 \mathrm{~kg}$ dan hasil tangkapan sampingan sebanyak $18.443 \mathrm{~kg}$. Persentase hasil tangkapan cakalang (72\% layak, 28\% tidak layak), baby tuna (100\% tidak layak), yellow fin tuna (51\% layak, 49\% tidak layak), layang, tongkol, lemadang, dan ikan lainnya (100\% layak). Keseluruhan ikan hasil tangkapan di KM Bintang Sampurna-B sesuai dengan jumlah sampel yang diukur, menunjukkan angka sebanyak 74\% layak tangkap dan $26 \%$ tidak layak tangkap.
\end{abstract}

Kata kunci: layak tangkap, Samudera Hindia, selektivitas 


\section{PENDAHULUAN}

Indonesia merupakan sebuah negara kepulauan dengan memiliki luas wilayah laut yang mencapai 5,8 juta $\mathrm{km}^{2}$, mempunyai potensi yang besar dalam sektor perikanan, khususnya perikanan tangkap. Dengan besarnya luas wilayah laut, sektor perikanan memiliki peranan strategis dalam pembangunan nasional. Selain itu, sektor perikanan tangkap ternyata juga memiliki peran yang besar terhadap produksi perikanan tangkap di dunia. Berdasarkan data FAO (2020), menyatakan Indonesia merupakan negara yang memiliki kontribusi terhadap perikanan tangkap dunia sebesar 7,48\% (7,2 juta ton ikan) pada tahun 2018. Besarnya peranan perikanan tangkap Indonesia di dunia, maka dari itu Fauzi dan Anna (2002) menyatakan bahwa sumberdaya perikanan sebagai salah satu aset penting negara apabila dikelola secara baik dan memberikan manfaat maksimum bagi masyarakat.

Indonesia sendirisejakditerbitkannya PERMEN KP No. 18 Tahun 2014 memiliki 11 wilayah perikanan yang perlu dikelola secara baik antara lain yaitu WPP 572 dan 573. WPP 572 dan 573 yang terletak di perairan Samudera Hindia dikenal memiliki potensi hasil perikanan tangkap yang cukup besar, utamanya yaitu dari kelompok ikan pelagis seperti cakalang (Katsuwonus pelamis), tuna mata besar (Thunnus obesus), layang (Decapterus macarellus), madidihang (Thunnus albacerus), kembung (Rastrelliger spp), dan tongkol (Euthynnus affinis). Hal ini didukung oleh pernyataan Kusdiantoro et al. (2019) yaitu salah satu jenis sumber daya ikan yang memiliki potensi besar dari kelompok ikan pelagis besar adalah Tuna, Tongkol, Cakalang (TTC). Selain memiliki potensi, ikan-ikan tersebut merupakan ikan yang memiliki nilai ekonomis tinggi. Seperti yang disampaikan oleh Genisa (1999) bahwa jenis ikan yang memiliki nilai ekonomis tinggi diantaranya yaitu cakalang, tuna, mata besar, madidihang, albakor, tongkol krei, dan tongkol lisong. Selain itu, jenis lain yang memiliki nilai cukup ekonomis diantaranya kembung, layang, tembang, sunglir, dan lemuru (Katiandagho dan Kumajas 1989).

Besarnya nilai ekonomis yang didapat, membuat kegiatan eksploitasi ikan di Indonesia saat ini semakin tinggi dan cenderung mengabaikan daripada kelestarian sumberdaya ikan. Hal ini memberikan dampak yang cukup besar dan berpotensi terjadinya overfishing. Berdasarkan KEPMEN KP No 50 Tahun 2017, hampir semua wilayah pengelolaan perikanan Indonesia khususnya untuk ikan pelagis kecil dan besar telah mengalami kondisi fully-exploited yang termasuk diantaranya yaitu WPP 572 dan 573 . Salah satu penyebabnya karena nelayan cenderung menangkap ikan secara bebas dan tidak memperhatikan ukuran hasil tangkap. Dengan menurunnya ukuran ikan hasil tangkapan, ini merupakan salah satu tanda mulai terjadinya overfishing.

Salah satu cara dalam mengatasi kegiatan penangkapan ikan agar tidak terjadi overfishing yaitu dengan mengelola pembatasan ukuran ikan hasil tangkapan. Pengukuran ikan merupakan salah satu metode yang mudah dilakukan dan didapat untuk diolah menjadi sebuah informasi dasar menentukan pengelolaan perikanan. Menurut Zamroni dan Suwarso (2011) pengelolaan perikanan dapat ditentukan dengan kajian ilmiah berdasarkan status stok dan memerlukan data dan aspek biologi. Pembatasan dalam hal ukuran ikan yang layak tangkap dapat membantu proses selektivitas alat tangkap. Hal ini didukung pernyataan Pamenan et al. (2016) bahwa ukuran frekuensi panjang ikan dapat menjadi dasar dalam selektivitas alat tangkap seperti purse seine. Berdasarkan penjelasan tersebut, penelitian ini bertujuan untuk mengetahui ukuran ikan hasil tangkapan yang dilakukan oleh nelayan purse seine di WPP 572 dan 573. Maka dari itu diperlukan adanya data mengenai ukuran ikan yang tertangkap sehingga dapat dilakukan analisa untuk mengetahui kondisi perikanan yang terdapat di WPP 572 dan 573 yang sudah masuk kategori fully-exploited. Informasi ini dapat digunakan sebagai dasar dalam mengelola perikanan yang berkelanjutan dengan adanya selektivitas dari alat tangkap yang digunakan.

\section{METODE PENELITIAN}

Penelitian dilaksanakan pada Januari sampai April 2020 yang bertempat di Samudera Hindia atau berada di WPP 572 dan 573. Metode yang digunakan dalam penelitian ini yaitu metode survei dan melakukan pengambilan data secara langsung selama kegiatan penangkapan ikan dari bulan Januari hingga April 2020. Untuk pengumpulan datanya dilakukan dengan cara primer dan sekunder. 
Data primer diperoleh dari data sampling hasil tangkapan purse seine di Kapal KM Bintang Sampurna-B pada tiap kali setelah kegiatan hauling atau ikan didaratkan di kapal. Data primer yang dibutuhkan yaitu meliputi jenis dan ukuran hasil tangkapan. Data sekunder yang digunakan yaitu beberapa acuan dari hasil penelitian terdahulu yang membahas ukuran ikan yang layak tangkap. Hasil akhir diperoleh dengan menggunakan analisis deskriptif yang tersaji dalam bentuk tabel maupun grafik.

Pengambilan sampel dilakukan selama kegiatan penangkapan di KM Bintang Sampurna-B saat setelah melakukan hauling. Sampel yang diambil berdasarkan metode purposive sampling yakni dengan mengambil beberapa jenis ikan hasil tangkapan sesuai jenisnya masing-masing yang dianggap dapat mewakili keseluruhan ikan yang sudah ditangkap pada setiap selesai kegiatan hauling. Pemilihan sampel ikan dilakukan secara acak berdasarkan jenis ikan yang tertangkap saat proses penangkapan dilakukan. Pengambilan jumlah sampel ikan menggunakan loyang/ wadah dengan kapasitas ukuran berbeda. Kapasitas wadah yang besar berisikan 1820 ekor ikan, sedangkan untuk wadah kecil terisi 40-45 ekor ikan.

\section{HASIL DAN PEMBAHASAN}

\section{Hasil tangkapan}

Kegiatan penelitian ini mengikuti dari kegiatan pengoperasian penangkapan ikan KM Bintang Sampurna-B yang berlangsung selama empat bulan mulai dari bulan Januari hingga April 2020. Daerah pengoperasian penangkapan ikan ini berada di Wilayah Pengelolaan Perikanan (WPP) 572 dan 573 dengan menggunakan rumpon sebagai alat bantu dari pengoperasian penangkapan. Jumlah rumpon yang digunakan selama kegiatan penangkapan sebanyak 33 buah. Kegiatan penangkapan yang dilakukan KM Bintang Sampurna-B selama pengoperasiannya menggunakan alat tangkap purse seine dengan jumlah upaya yang dilakukan mencapai 54 kali setting yang dilakukan pada setiap rumponrumpon tersebut.

Hasil tangkapan utama yang menjadi target utama KM Bintang Sampurna-B adalah ikan cakalang, sementara hasil tangkapan sampingannya berupa ikan layang, ikan tongkol, ikan tuna dan lainnya. Jumlah keseluruhan hasil tangkapan yang telah dilakukan mendapat hasil sebanyak $75.878 \mathrm{~kg}$. Hasil tangkapan utama sebanyak $57.435 \mathrm{~kg}$ dan hasil tangkapan sampingan sebanyak $18.443 \mathrm{~kg}$ (Gambar 1).

Jumlah jenis ikan yang didapatkan dari keseluruhan hasil penangkapan mencapai delapan jenis ikan. Secara umum ikan cakalang dan baby tuna memiliki jumlah tangkapan terbanyak dan tertinggi dibandingkan dengan ke-delapan jenis ikan lainnya yang merupakan hasil tangkapan yang sama di KM Bintang Sampurna-B. Jumlah hasil tangkapan terbanyak berikutnya yaitu ikan layang dan untuk jumlah hasil tangkapan lainnya tersaji pada grafik dibawah ini (Gambar 2).

\section{Ukuran hasil tangkapan}

Hasil pengukuran ikan hasil tangkapan dilakukan selama empat bulan, mulai dari bulan Januari sampai April 2020. Hasil pengukuran tersebut dibedakan berdasarkan tiap jenis ikan yang ditangkap. Pengukuran panjang cagak dilakukan dengan cara meletakkan ikan di geladak kapal dan membentangkan meteran di atas badan ikan mulai ujung mulut ikan hingga pangkal ekor ikan. Pengukuran ikan dilakukan pada setiap selesai melakukan operasi setting di KM BSB, ukuran yang dihitung yaitu ukuran panjang cagak (fork length).

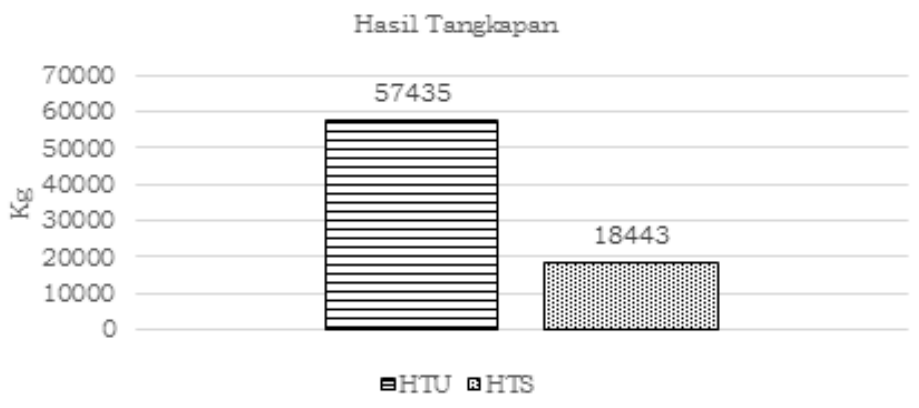

Gambar 1. Perbandingan hasil tangkapan 


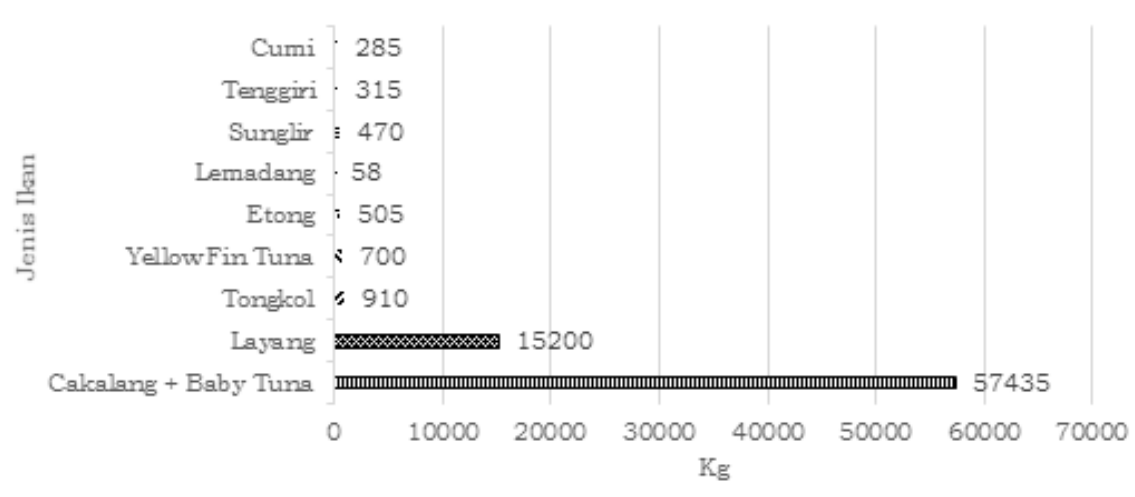

Gambar 2. Rekapitulasi hasil tangkapan

Ikan cakalang yang ditangkap di KM Bintang Sampurna-B memiliki panjang cagak antara $15-65 \mathrm{~cm}$ dan ukuran mayoritas ikan yang tertangkap berkisar panjang 46$50 \mathrm{~cm}$ sejumlah 201 ekor (Gambar 3).

Ikan lainnya yang tertangkap adalah ikan layang. Ikan layang termasuk ke dalam ikan pelagis kecil (Genisa 1999). Ikan layang merupakan salah satu komunitas perikanan pelagis kecil yang penting di Indonesia. Jenis ikan layang yang tertangkap di KM Bintang Sampurna-B adalah ikan layang biru (Decapterus macarellus). Ikan layang yang ditangkap memiliki panjang cagak antara 16-35 cm dengan ukuran mayoritas yang tertangkap yaitu 26-30 cm (Gambar 4).
Hasil tangkapan sampingan lainnya yang didapatkan yaitu ikan tongkol. Ikan tongkol lisong memiliki gigi yang kecil dan meruncing serta memiliki tulang ekor yang kuat dan didukung oleh dua tulang bercabang pada sirip ekor (Collette dan Aadland 1996 dalam Bachri 2016). Ikan tongkol yang tertangkap di KM Bintang Sampurna-B adalah tongkol lisong (Auxis rochei). Ikan tongkol lisong yang tertangkap di KM BSB memiliki kisaran panjang cagak antara 21-35 $\mathrm{cm}$ dengan berat kurang dari 1 kg per ekornya. Mayoritas ikan tongkol yang tertangkap yaitu berukuran panjang cagak 26-30 cm (Gambar 5).

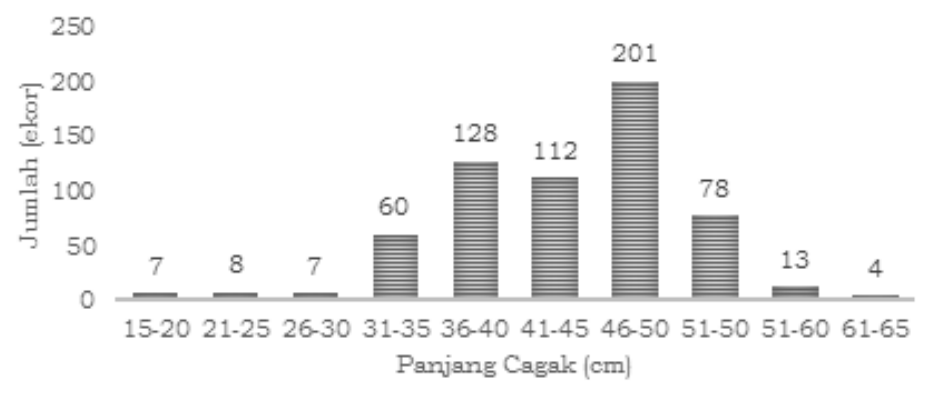

Gambar 3. Pengukuran panjang cagak ikan cakalang

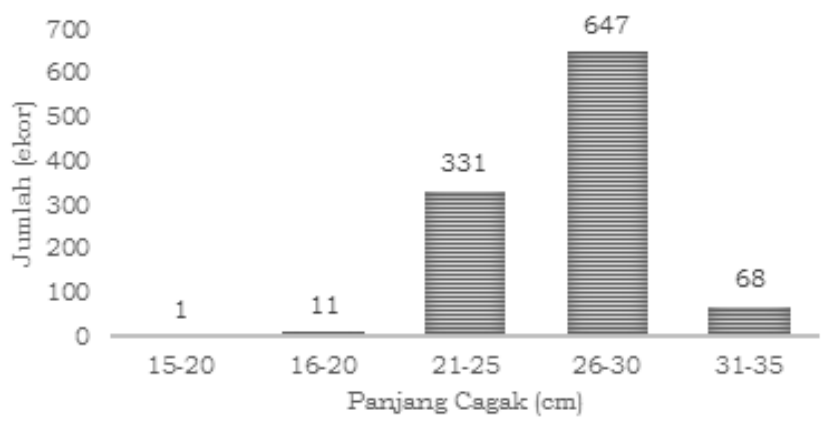

Gambar 4. Pengukuran panjang cagak ikan layang 


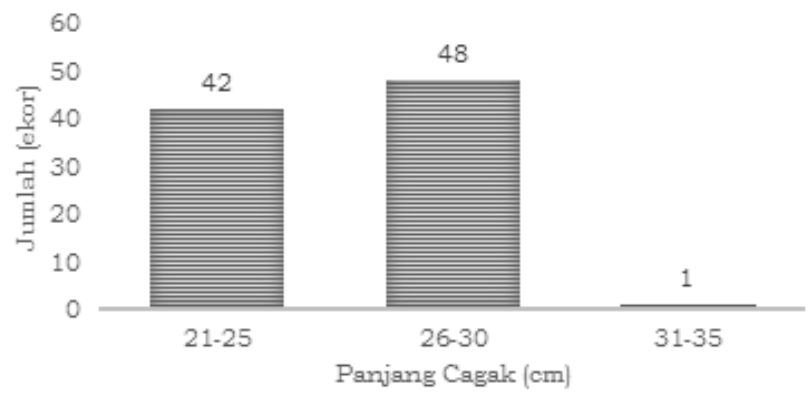

Gambar 5. Pengukuran panjang cagak ikan tongkol

Ikan lainnya yang tertangkap yaitu ikan tenggiri banci (Acanthocybium solandri). Ciri-ciri ikan tenggiri ini adalah mempunyai tubuh yang panjang, berbentuk torpedo dan merupakan perenang cepat. Tenggiri mempunyai mulut yang lebar dengan ujung runcing, gigi pada rahang gepeng dan tajam. Memiliki dua sirip punggung dan badannya berwarna biru gelap atau biru kehijauan. Saat dewasa tenggiri terdapat garis berwarna abu-abu pada bagian perut (Septiarini 2008) ikan tenggiri yang tertangkap di KM Bintang Sampurna-B memiliki panjang cagak antara 55-105 cm dengan mayoritas tertangkap pada ukuran 81-85 $\mathrm{cm}$ (Gambar 6).

Ikan yang tertangkap lainnya yaitu ikan lemadang. Ikan lemadang memiliki karakteristik morfologis dicirikan oleh warna kuning emas pada bagian sisi, serta warna biru cerah dan hijau di bagian samping dan belakang. Ikan berjenis kelamin jantan dewasa memiliki dahi yang menonjol di bagian atas kepala, sedangkan betina memiliki kepala yang bulat (Collette 1999 dalam Chodrijah dan Nugroho 2016). Ikan lemadang yang tertangkap di KM Bintang Sampurna-B memiliki panjang berkisar antara $60-100 \mathrm{~cm}$ dan mayoritas tertangkap pada panjang cagak 86-90 cm (Gambar 7).

Ikan hasil tangkapan lainnya adalah ikan tuna sirip kuning (Thunnus albacares). Menurut Collette (1994) dalam Muqsit
(2016), ikan tuna sirip kuning termasuk jenis ikan berukuran besar, mempunyai dua sirip dorsal dan sirip anal yang panjang. Sirip dada (pectoral fin) melampaui awal sirip punggung (dorsal) kedua, tetapi tidak melampaui pangkalnya. Ikan tuna sirip kuning biasanya membentuk (schooling) gerombolan di bawah permukaan air. Ikan tuna sirip kuning yang tertangkap di KM Bintang Sampurna-B kebanyakan masih tergolong juvenile atau berukuran kecil. Panjang cagak ikan yang tertangkap antara 21-140 cm dengan mayoritas ikan yang tertangkap pada ukuran 41-50 cm (Gambar 8).

Jenis ikan lainnya yang tertangkap adalah ikan sunglir (Elagastis bipinnulatus). Ikan sunglir memiliki bentuk tubuh memanjang. Kepala dan moncong menunjuk atau meruncing dengan mulut yang kecil. Bentuk badan memanjang menyerupai cerutu. Memiliki warna tubuh biru kehijauan pada punggung dan perut berwarna keputihan. Terdapat dua garis membujur pada sisi badan berwarna biru muda dan terdapat juga strip berwarna kuning (Istikowati 2017). Ikan sunglir yang tertangkap di KM Bintang Sampurna-B memiliki panjang cagak berkisar antara 0-110 cm dengan mayoritas tertangkap pada ukuran 21-30 cm (Gambar 9).

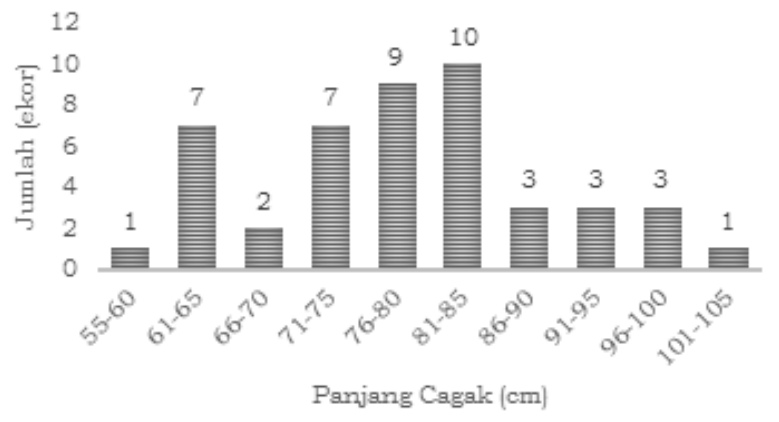

Gambar 6. Pengukuran panjang cagak ikan tenggiri 


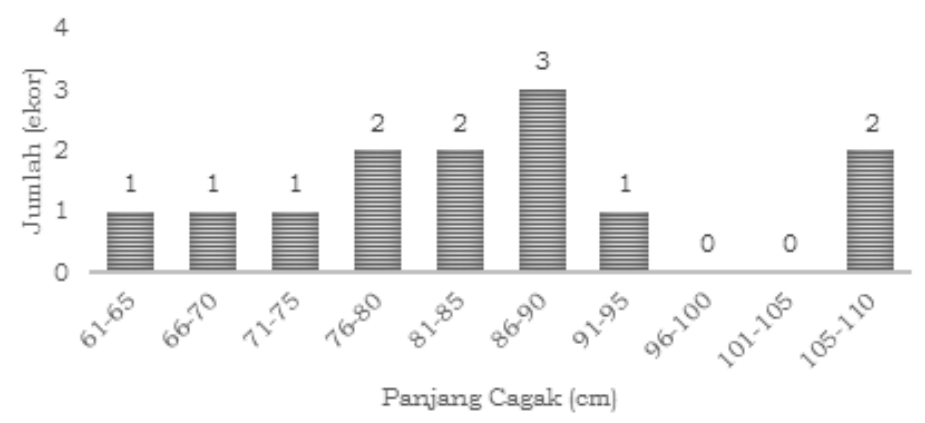

Gambar 7. Pengukuran panjang cagak ikan lemadang

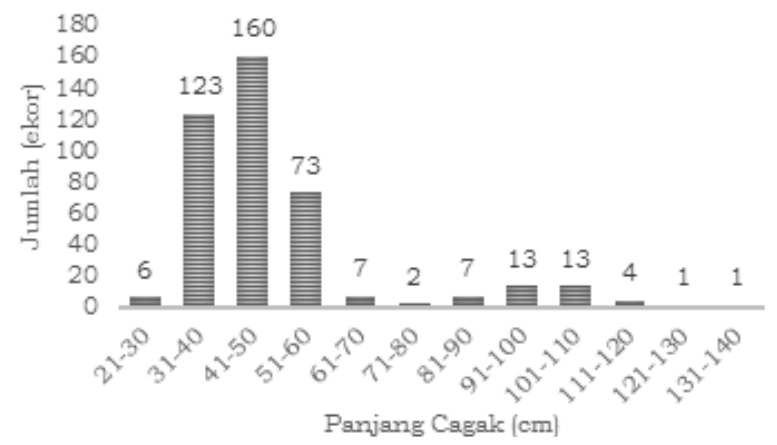

Gambar 8. Pengukuran panjang cagak ikan tuna sirip kuning

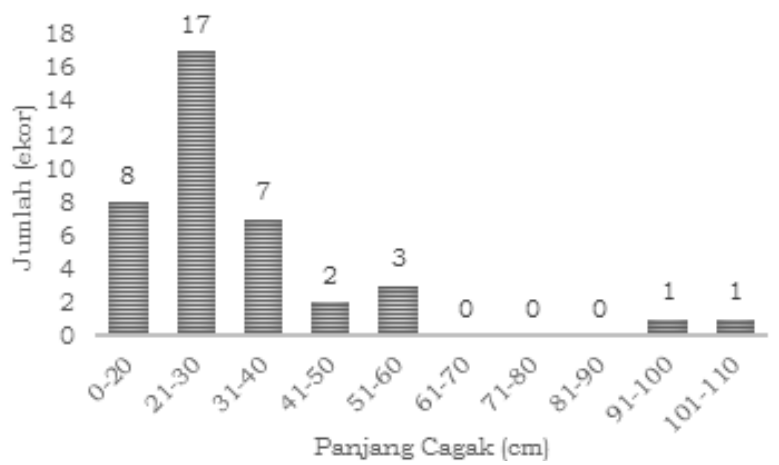

Gambar 9. Pengukuran panjang cagak ikan sunglir

Jenis ikan lain yang tertangkap adalah ikan kambing/etong (Canthidermis maculata). Ikan ini memiliki tubuh berwarna gelap abu-abu kehitaman dan bersisik keras dan kasar menyerupai bentuk kulit jeruk. Memiliki duri pada bagian punggung atas yang tajam. Ikan ini mempunyai gigi yang kuat dan menyerupai gigi manusia. Ikan kambing/etong yang tertangkap di KM Bintang Sampurna-B memiliki panjang cagak antara $15-40 \mathrm{~cm}$ dengan mayoritas tertangkap pada ukuran 21-30 cm (Gambar $10)$.

\section{Analisa layak tangkap}

Hasil tangkapan di KM Bintang Sampurna-B dibedakan menjadi dua kategori yaitu hasil tangkapan utama dan hasil tangkapan sampingan. Setiap jenis dari masing-masing hasil tangkapan memiliki standar ukuran layak tangkap yang berdasarkan tingkat kematangan gonad atau ukuran pertama kali matang gonad atau yang biasa disebut Length of First Maturity (Lm). Berdasarkan penelitian terdahulu nilai Lm dari ikan ditentukan dari 
panjang cagak/Fork Length (FL) yang dapat menentukan layak tangkap atau tidaknya ikan tersebut. Ketentuan Lm dari ikan yang ditangkap dapat dilihat pada Tabel 1. Ikan hasil tangkapan di KM Bintang Sampurna-B dapat ditentukan layak tidaknya tangkapan tersebut melalui sebuah pengolahan data menggunakan Ms.Excel.

Persentase hasil tangkapan utama yaitu cakalang menunjukkan sebesar $72 \%$ diantaranya layak tangkap dan $28 \%$ sisanya tidak layak tangkap. Persentase baby tuna adalah $100 \%$ tidak layak tangkap karena ikan yang tertangkap masih tergolong juvenile. Persentase yellow fin tuna sebesar 51\% layak tangkap dan 49\% tidak layak tangkap. Persentase layak tangkap tenggiri masing-masing sebesar 50\%, dan untuk layang, tongkol, lemadang, dan ikan lainnya memiliki persentase layak tangkap 100\% karena telah memenuhi nilai Lm jenis ikan tersebut (Gambar 11). Data yang digunakan dalam pengolahan grafik pie yang menunjukkan persentase layak dan tidak layaknya hasil tangkapan di KM Bintang
Sampurna-B tersebut diperoleh dari data sampel ikan yang dilakukan selama kegiatan penangkapan. Berdasarkan grafik tersebut, beberapa jenis ikan memiliki persentase layak tangkap yang memenuhi nilai Lm dari jenis ikan tersebut, ada juga beberapa jenis ikan yang presentase layak tangkapnya tidak memenuhi Lm jenis ikan tersebut.

Sementara untuk presentase layak tangkap dari keseluruhan ikan hasil tangkapan di KM Bintang Sampurna-B sesuai dengan jumlah sampel yang diukur, menunjukkan angka sebanyak 74\% layak tangkap dan 26\% tidak layak tangkap. Jenis ikan yang memiliki presentase layak tangkap tertinggi adalah ikan layang, ikan tongkol, ikan lemadang, dan ikan jenis lainnya. Sementara ikan yang memiliki presentase tidak layak tangkap tertinggi adalah ikan tuna dikarenakan masih banyaknya juvenille ikan tuna yang tertangkap. Jumlah sampel dan jenis ikan yang telah diukur dan didata dalam penentuan layak tangkap ikan hasil tangkapan selama kegiatan penangkapan (Gambar 12).

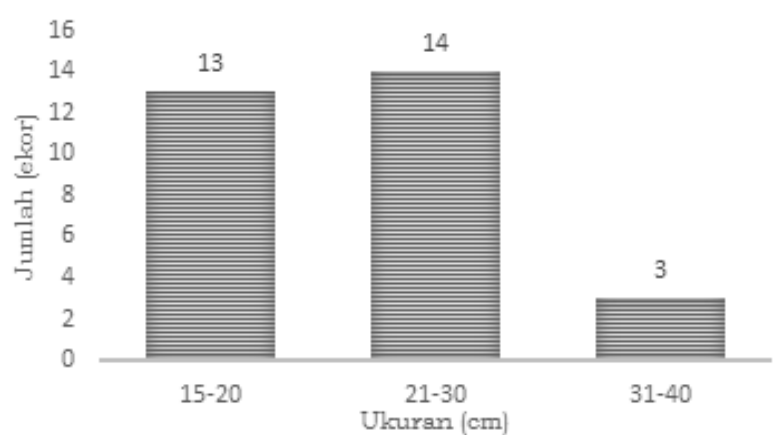

Gambar 10. Pengukuran panjang cagak ikan kambing/etong

Tabel 1. Referensi Lm ikan hasil tangkapan

\begin{tabular}{lccc}
\hline \multicolumn{1}{c}{ Jenis Ikan } & Lokasi & Lm & Referensi \\
\hline Cakalang & Maluku & $40 \mathrm{~cm}$ & Karman et al. (2016) \\
Layang Biru & WPP 573 & $10,25-32,25 \mathrm{~cm}$ & Zamroni et al. (2019) \\
Tongkol Lisong & WPP $572-573$ & $35 \mathrm{~cm}$ & Widodo et al. (2014) \\
Yellow Fin Tuna & Samudera Hindia & $60-85$ (juvenil), & Marion et al. (2008) dalam \\
& Bagian Timur & $105-118 \mathrm{~cm}$ & Novitasari et al. (2019) \\
Tenggiri & WPP 573 & $79,3-81,6 \mathrm{~cm}$ & Noegroho et al. (2018) \\
Lemadang & WPP 573 & $56 \mathrm{~cm}$ & Prayitno et al. (2017) \\
Sunglir & Samudera Atlantik & $64,6 \mathrm{~cm}$ & Pinheiro et al. (2011) \\
Ikan Kambing & Atlantik Timur & $31,86 \mathrm{~cm}$ (jantan) & N'guessan et al. (2017) \\
& & $32,59 \mathrm{~cm}$ (betina) & \\
\hline
\end{tabular}



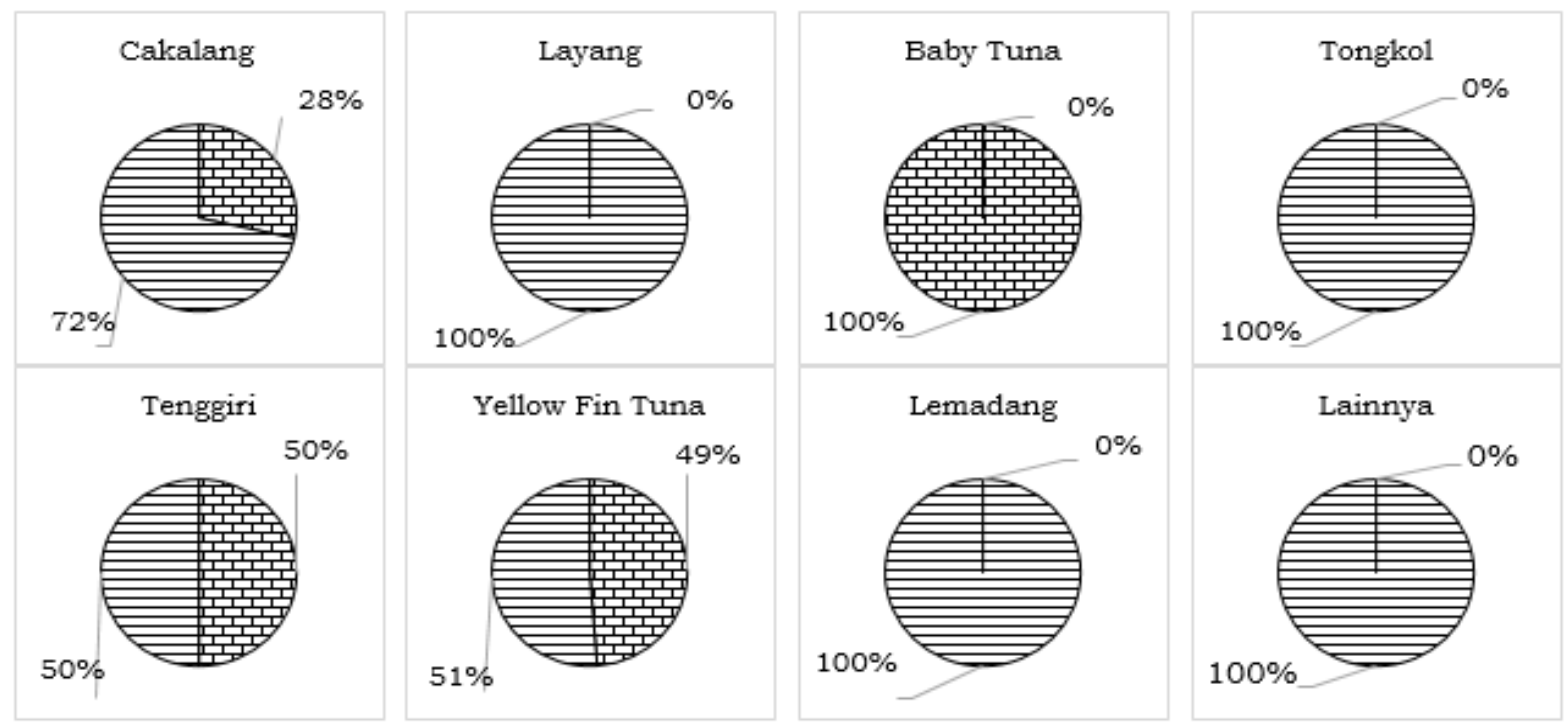

Gambar 11. Persentase layak tangkap tiap jenis ikan

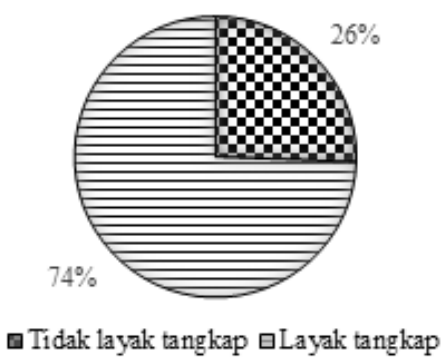

Gambar 12. Persentase ikan layak tangkap secara keseluruhan

\section{KESIMPULAN DAN SARAN}

\section{Kesimpulan}

Berdasarkan dari hasil kegiatan penangkapan ikan KM Bintang Sampurna-B selama empat bulan, hasil tangkapan utamanya yaitu ikan cakalang sedangkan hasil tangkapan sampingannya ikan tuna sirip kuning (Thunnus albacares), ikan layang (Decapterus macarellus), tongkol lisong (Auxis rochei), ikan lemadang (Coryphaena hippurus), ikan sunglir (Elagastis bipinnulatus), ikan kambing/ etong (Canthidermis maculata), dan ikan tenggiri (Scomberomerus comersonit). Persentase layak tangkap total hasil tangkapan di KM Bintang Sampurna-B mencapai 74\% layak tangkap dan 26\% tidak layak tangkap, dengan total sampel ikan hasil tangkapan sebanyak 2.304 ekor. Sementara untuk persentase layak tangkap per jenis ikan yang ditangkap adalah ikan cakalang mencapai $72 \%$ layak tangkap, ikan tuna sirip kuning 37\% layak tangkap, ikan tongkol $100 \%$ layak tangkap, ikan tenggiri $50 \%$ layak tangkap, ikan lemadang 100\% layak tangkap, dan ikan lainnya sebanyak $100 \%$ layak tangkap. Dari sekian banyak ikan yang layak tangkap, terdapat hasil tangkapan yang masih dikategorikan belum layak tangkap yaitu ikan baby tuna.

\section{Saran}

Berdasarkan dari hasil penangkapan, masih terdapat ukuran ikan yang masih belum layak tangkap dan cukup banyak ditemukan jumlah ikan yang merupakan hasil tangkapan sampingan (bycatch) sehingga perlu diperhatikan kembali dalam selektivitas target hasil penangkapan. Selain itu perlu diperhatikan juga dalam membatasi ukuran mata jaring (mesh size) dari alat tangkap yang digunakan. Pembatasan ini diharapkan agar ikan-ikan yang masih kategori juvenile dapat berkembang dan dapat terus terjaga keberadaannya. 


\section{DAFTAR PUSTAKA}

Bachri S. 2016. Analisis Bioekonomi Ikan Tongkol Lisong (Auxis rochei) dengan Alat Tangkap Payang di PPN Palabuhanratu Jawa Barat. Fakultas Ekonomi dan Manajemen [Skripsi]. Bogor: Institut Pertanian Bogor.

Chodrijah U, Nugroho D. 2016. Struktur Ukuran dan Parameter Populasi Ikan Lemadang (Coryphaena hippurus Linnaeus) di Laut Sulawesi. Jurnal BAWAL. 8(3): 147-158.

FAO. 2020. FAO Yearbook. Fishery and Aquaculture Statistics 2018. Rome.

Fauzi A, Anna Z. 2002. Penilaian Depresiasi Sumber Daya Perikanan Sebagai Bahan Pertimbangan Penentuan Kebijakan Pembangunan Perikanan. Jurnal Pesisir dan Lautan. 4(2): 3649.

Genisa AS. 1999. Pengenalan Jenis-Jenis Ikan Laut Ekonomi Penting di Indonesia. Oseana. 24(1): 17-38.

Istikowati R. 2017. Identifikasi Isi Lambung Ikan Sunglir (Elagatis bipinnulata Quoy dan Gaimard, 1825) yang Didaratkan di Pelabuhan Perikanan Nusantara (PPN) Prigi Trenggalek, Jawa Timur. Malang: Fakultas Perikanan dan Ilmu Kelautan, Universitas Brawijaya.

Karman A, Martasuganda S, Sondita MFA, Baskoro MS. 2016. Basis Biologi Cakalang sebagai Landasan Pengelolaan Perikanan Berkelanjutan di Provinsi Maluku Utara. Jurnal Ilmu dan Teknologi Kelautan Tropis. 8(1): 159-173.

Katiandagho EH, Kumajas HJ. 1989. Metode Penangkapan Ikan. Sulawesi: Fakultas Perikanan, Universitas Sam Ratulangi.

[KEPMEN KP] Keputusan Menteri Kelautan dan Perikanan Republik Indonesia Nomor 50/KEPMEN-KP/2017 tentang Estimasi Potensi, Jumlah Tangkapan yang diperbolehkan, dan Tingkat Pemanfaatan Sumber Daya Ikan di Wilayah Pengelolaan Perikanan Negara Republik Indonesia.

Kusdiantoro, Achmad F, Sugeng HW, Bambang J. 2019. Perikanan Tangkap Indonesia: Potret dan Tantangan Keberlanjutannya. Jurnal Sosial Ekonomi Kelautan dan Perikanan. 14(2): 145-162.

Muqsit A. 2016. Pengelolaan Perikanan Tuna
Sirip Kuning (Thunnus albacares) dengan Menggunakan Rumpon di Perairan Kaur Provinsi Bengkulu. Program Studi Teknologi Perikanan Laut [Skripsi]. Bogor: Institut Pertanian Bogor.

Noegroho T, Hidayat T, Chodriyah U, Patria MP. 2018. Biologi Reproduksi Ikan Tenggiri (Scomberomorus commerson) di Perairan Teluk Kwandang Laut Sulawesi. Jurnal BAWAL. 10(1): 6984.

Novitasari F, Nelwan AFP, Fahrum A. 2019. Struktur Ukuran Ikan Madidihang (Thunnus albacares) Berdasarkan Rumpon di Teluk Bone Kabupaten Luwu. Prosiding Simposium Nasional Kelautan dan Perikanan VI. Makassar: Universitas Makassar.

N'Guessan Y, N'Guessan CD, Amande JM, Kouame JPA, Abekan E, Assan FN, N'Da K. 2017. Sex Ratios, Maturity Stages, Size of First Maturity and Condition Factor of the Canthidermis maculata Capture in the Eastern Atlantic. International Journal of Biological and Chemical Sciences. 11(6): 2876-2886.

Pamenan AR, Sunarto S, Nurruhwati I. 2016. Selektivitas Alat Tangkap Purse Seine di Pangkalan Pendaratan Ikan (PPI) Muara Angke Jakarta. Jurnal Perikanan Kelautan. 7(2): 97-102.

[PERMEN KP] Peraturan Menteri Kelautan dan Perikanan Republik Indonesia Nomor 18/PERMEN-KP/2014 tentang Wilayah Pengelolaan Perikanan Negara Republik Indonesia.

Pinheiro PB, Hazin FHV, Travassos P, Oliveira PGV, Carvalho F, Rego MG. 2011. The Reproductive Biology of the Rainbow Runner, Elagatis bipinnulata (Quoy \& Gaimard, 1825) Caught in the São Pedro and São Paulo Archipelago. Brazilian Journal of Biology. 71(1): 99-106.

Prayitno MRE, Simbolon D, Yusfiandayani R. 2017. Produktivitas Alat Tangkap yang Dioperasikan di Sekitar Rumpon Laut Dalam. Jurnal Perikanan dan Kelautan. 8(1): 101-112.

Septiarini T. 2008. Karakteristik Mutu Ikan Tenggiri (Scomberomorus commersonii) di Kecamatan Manggar, Kabupaten Belitung Timur. Fakultas Perikanan dan Ilmu Kelautan [Skripsi]. Bogor: Institut Pertanian Bogor. 
Widodo AA, Satria F, Sadiyah L. 2014. Status Pemanfaatan dan Pengelolaan Sumberdaya Ikan Tuna Neritik di Samudera Hindia WPP 572 dan 573. Jurnal Kebijakan Perikanan Indonesia. 6(1): 23-28.

Zamroni A, Suwarso. 2011. Studi Tentang Biologi Reproduksi Beberapa Spesies Ikan Pelagis Kecil di Perairan Laut Banda. Jurnal BAWAL. 3(5): 337344.

Zamroni A, Kuswoyo A, Chodrijah U. 2019. Aspek Biologi dan Dinamika Populasi Ikan Layang Biru (Decapterus macarellus Cuvier 1833) di Perairan Laut Sulawesi. Jurnal BAWAL. 11(3): 137-149. 